\title{
INNOVATIVE TECHNOLOGIES AS A MEANS OF FORMATION OF VISUAL-COMMUNICATION ENVIRONMENT OF THE MODERN CITY
}

\author{
Professor, Doctor of Sciences in Architecture, Dubinskiy V.P. \\ PhD student, Nesen A. A. \\ Ukraine, Kharkiv, Kharkiv National University of Construction and Architecture \\ Ukraine, Kharkiv, O.M.Beketov National University of Urban Economy in Kharkiv
}

DOI: https://doi.org/10.31435/rsglobal_wos/31032019/6388

\section{ARTICLE INFO}

Received: 18 January 2019

Accepted: 26 March 2019

Published: 31 March 2019

\section{KEYWORDS}

visual-communication environment, innovative technologies, modern city.

\begin{abstract}
The article considerers innovative technologies as a means of formation of a visual-communication environment of the modern city. The article estimates the impact of innovative technologies on the architectural appearance of the modern city, the role of these technologies in the improvement of anthropogenic and natural elements of the urban environment is investigated. The points of view of specialists from different areas about the concepts of "city", "urban environment" are presented, the current trends in the study of the phenomenon of the modern city and its component system are analyzed. The definition of the visual-communication environment of the modern city is given, attention is focused on its distinctive features. The five prevailing innovation directions (architectural bionics, adaptive architecture, arcology, green architecture, smart architecture) are defined, the principles and technologies of which are introduced into the urban environment. Characteristic features are studied and the followers of these trends are enumerated, as well as their realized examples of introducing the innovative directions into the modern cities' environment. The ability of the visual communication environment to adapt and transform is considered. An analysis is made of the role of a man as a resident-user of the modern city in the chain of relationships between the architecture and innovation.
\end{abstract}

Citation: Dubinskiy V. P., Nesen A. A. (2019) Innovative Technologies as a Means of Formation of Visual-Communication Environment of the Modern City. International Academy Journal Web of Scholar. 3(33). doi: 10.31435/rsglobal_wos/31032019/6388

Copyright: (C) 2019 Dubinskiy V. P., Nesen A. A. This is an open-access article distributed under the terms of the Creative Commons Attribution License (CC BY). The use, distribution or reproduction in other forums is permitted, provided the original author(s) or licensor are credited and that the original publication in this journal is cited, in accordance with accepted academic practice. No use, distribution or reproduction is permitted which does not comply with these terms.

Introduction. The city is a complex object, which is studied by representatives of various sciences and applied disciplines. Currently, there is no single definition for the term "city" as representatives of different scientific fields suggest their own definitions, based on their fundamental constants. It is generally recognized that the development of a city is a complex process in which all components and subsystems are involved. In the theory of urban planning, a city is defined as "an environment that includes a system of social institutions that support the life activities of the urban population, or a human-created environment necessary for diverse activities (Glazychev, 1984). In sociology, a city is considered as a dynamic system functioning through an interconnection of substructures (Faizullin, 2008). But all the researchers are united in the fact that the city is the phenomenon, the study of which is relevant for the present day. 
In the 1920s, American sociologists introduced the term "urban environment" for the first time and posed the problem of "transformation of interpersonal communication under the influence of urbanization" (Trushchenko, 1983). In architecture and construction, according to A.V. Ikonnikov, the concept of "urban environment" includes everything that forms the material structure of a city beginning "from elementary cells of the internal space of buildings to vast territories of residential, planning and industrial areas of the city ... The necessary "filling" of the material and spatial backbone that the architecture creates, namely, equipment and furniture in buildings, means of transport, various signaling systems and technical devices in the streets - in a word, everything which is necessary for the city functioning" is included into the concept (Ikonnikov, 1973).

Modern researchers consider the city as a multifunctional socio-cultural organism that no longer represents an exclusively life environment as it used to be originally. This is a new complex multifaceted object, consisting of various systems and supportive components affecting all areas of human life and including the man. In an era of global processes, when everything is automated and digitized, when the tempo of changes of external conditions does not coincide with the tempo of response of internal urban systems, scientists face a number of problems having different nature. All these changes stimulated the emergence of many new philosophical concepts and trends resulting in the development of new scientific approaches to understanding and organizing the urban environment. Besides, new dynamic, intellectual systems of the city appear, which require special attention and a detailed comprehensive study. The task of specialists in different areas is to coordinate all efforts to achieve a functional and structural integrity of the city.

Today, a city is a collection of several intelligent systems interconnected by a single goal to satisfy all the needs and demands of the residents. One of such systems and important structural components of the modern city is the visual communication environment.

The results of the research.

What is a visual communication environment? What is its role in the formation of the modern city?

Visual-communication environment (VCE) - is an independent functional object of the architectural design; an hierarchical system of the city, the forming components of which are the anthropogenic and natural elements of the urban environment, equipped with visual and communication means.

VCE formation took place long before the appearance of developed cities, as we can see them now. Its first manifestations were cave paintings in the caves of primitive people, relief and hieroglyphs on the walls of ancient Egyptian temples, signs and plates on the streets of cities in the Middle Ages. But gradually, with the evolution and development of scientific and technological progress, visual communication environment grew from primitive elements into an independent system, with its own hierarchical framework and connecting components.

An important difference of VCE from other systems is that it performs a few different functions (adaptation, orientation, information, ecologization, etc.) and is directly the "carrier" of innovation in the modern city. VCE, which includes innovative technologies, allows you to create a high-quality, comfortable urban environment, while maintaining and updating the existing facilities of the city.

As it was described earlier, the formation of the visual-communication environment took place as early as in the primitive time, from which it can be noted that the development of the VCE depends directly on the level of the society development and the qualitative indicators of the urban environment. Currently, in the digital age, it has reached its peak.

Considering the current trends in the world, one can notice a global introduction of innovative technologies in all spheres of human activities. At the moment, five innovative areas dominate, the technologies and principles of which are being introduced into the urban environment and are considered in this article: architectural bionics, adaptive architecture, arcology, green architecture and smart architecture. All these methods of non-linear shaping are part of the VCE, which, in turn, is one of the constituent parts of the modern city. Hereafter, a description of each innovative direction with characteristic existing examples is given.

Architectural bionics is an applied science on using principles of living nature for technical devices and systems, i.e. using natural forms, qualities, functions and structures in industrial analogues (Zhdanov, 2016). Simply defined, bionics is a combination of biology and technology. In foreign publications, the term biomimetics is often used as an approach to creation of technological devices, in which an idea is borrowed from the animated nature. 
Leonardo da Vinci, who was trying to build an ornithopter, a flying machine with the wings resembling those that birds have, can be considered a pioneer in introducing the principles of bionics.

In the architectural design, the first attempts to use natural forms were undertaken by A. Gaudi. Vivid examples of natural imitations may be considered his design of the private villas of Kos Batló and Casa Mila. After the construction of the Goetheanum in 1921 by the architect Rudolf Steiner, the bionics became even more popularized.

Today, bionics is developing in many areas - with the advent of cybernetics, its capabilities have become more extensive, which allows to create new devices, mechanisms and technologies, building materials, etc. Architectural bionics addresses the issues of structure formation of living tissues, is engaged in the analysis of the constructive systems of living organisms, which enables creating new building technologies based on economical and energy-saving materials. Besides, new unique designs and forms are designed imitating natural specimens that change and enrich the architectural image. The bright examples in architecture are the projects of S. Calatrava, V. Callebaut, A. Lovag, J. Senosiain, P. Nervi and others.

The characteristic features of the architectural bionics are the following:

- adherence to natural principles;

- independence from the laws of geometry;

- use of biomaterials and biotechnologies.

Adaptive architecture is an area of architectural practice that analyzes the state of the environment adapting its shape, color or function to the goals of maximum compliance with the requirements of operation.

The main principle of adaptive architecture is that with the help of technology all the boundaries between a person and the environment in which he/she is located are erased. Such a dynamic architecture is able to "understand" people and "respond" to them through interactive media devices. The followers of this trend believe that it will bring the architecture to a new level of functionality, aesthetic appeal and energy efficiency.

For the first time, the term and concept of the adaptive architecture was derived by a cybernetician Nicholas Negroponte, who first suggested that the architecture could be represented as a computer capable of responding to and interacting with the user (Negroponte, 2018).

With the development of cheap and energy-efficient technologies in various advanced areas (such as sensors, transducers, display devices, tensegrity structures, virtual reality technologies, threedimensional devices), using of which changes the concept of the architecture and environment of a modern city, and indicates its powerful hidden potential, the number of objects of adaptive architecture is growing every day. Currently, supporters of this trend are trying to radically revise the entire architectural practice. Good examples are the works "Gylomorphic Canopy" and "Breathing Wall" by B. Farahi, "Hydroskin Meteor-Sensitive Arbor" by A. Menges and O. Krieg, "Responding Media" by M. Kruger, etc.

Distinctive features of adaptive architecture are:

- use of sensory systems;

- use of reactive elements in the structures of architectural objects;

- ability of objects to transform and adapt in accordance with the conditions of the environment in which they are located.

Arcology is an architectural concept that takes environmental factors into account when designing human habitats. In a narrower sense, this is an idea of building large, self-sufficient multilevel structures (hyperstructures) that can accommodate the population of the whole city, thereby reducing the negative impact of settlements on the environment.

The founder of this concept is an architect Paolo Soleri, whose project Arcosanti is the only practical implementation of arcology (Soleri, 2006).

In addition to Arcosanti, there are a number of conceptual projects, such as the Tokyo X-Seed 4000, Seoul Commune 2026, N. Foster's Crystal Island and many others.

The specific features of this architectural direction are:

- design of self-sufficient and environmentally friendly arcologies;

- creation of three-dimensional hyperstructures;

- construction of environmentally friendly facilities. 
Green architecture is a branch of architecture that suggests to design and construct buildings that have a minimal environmental impact (Look at Me, 2019).

An active introduction of green buildings began in the middle os 1970s, when the world began to actively seek solutions for the conservation of natural resources. Green walls and roofs began to appear one after another in the urban environment of large cities. F. Hundertwasser is rightly considered the creator of green architecture. In his projects, the architect consistently returned to the nature the territories and spaces occupied by people.

Today, the topic of ecologically friendly, green architecture continues to be relevant. Its followers, such as architect W. McDonagh, designer P. Blank, architectural bureaus Herzog \& de Meuron, Mass Studies, give plants an important role in maintaining the environmental friendliness of the city.

The main differences of the green architecture are:

- environmental friendliness;

- use of the principles of energy conservation and reduction of the volume of new construction (use of old buildings or materials from them in new buildings);

- predominance of smooth forms and lines.

Smart architecture is a strategic development of a "smart" network, which combines various factors of urban development into a single system, with the introduction of IT tools and smart technologies, methods, and calculations. It is a system consisting of physical, digital, and communication components (Hinte, 2003).

Smart architecture originated in the 1980s in the studio of the architect Frank Gehry. To improve the quality of life of the residents of a particular architectural object, architects began to interact with engineers, sociologists, developers, artists, psychologists and the information obtained was processed and used in the digital modeling of buildings. Such an integrated approach to the design of new architectural objects allows creating a unique city structure that responds to its users. Examples of such smart objects include street lights that show up only when a person or a car approaches; smart parking, where the platforms carry a car to a designated place; smart traffic lights, smart crossings, security system sensors, smart homes, etc.

Distinctive features of the smart architecture include:

- establishing a feedback between the city and its citizens, improvement of the environment (comfort, safety, environmental friendliness);

- a unified system of communication and information technologies with the Internet of things;

- collection, transmission and analysis of data.

All the above technologies and devices of the five priority innovation areas together form the visual communication environment of the modern city. As a means of forming VCE, innovative technologies extend to four levels: element, building, space, city. Each level has its own characteristics, distinctive features and functionality, which in the complex makes it possible to create a coherent and harmonious urban environment.

Innovative technologies, as a means of forming VCE, can be represented in the modern city in the form of the following components:

- bionic objects that act as landmarks and dominants of the city;

- adaptive devices that react and respond to the requests from the residents;

- microarcology, performing several functions simultaneously and acting as a visual communication hub in the city;

- elements of green architecture that support the environmental friendliness of the city, but they can also serve as important architectural points;

- smart objects supplemented by sensor and navigation systems, smart lamps, audio guides.

It is worth noting that in addition to the important role of innovative technologies, the person is also important in the formation of visual communication environment. In addition to being directly a resident of the city, he is also an active user of all devices and systems and is the main guiding item in the complex relationship between architecture and the modern city. The man, using the formed image of the urban environment, is able to study and adapt the city to the processes of his/her daily activities, thereby contributing to the development of quality indicators of the environment. On the other side, the city influences a person, organizing his/her reality, influencing the ideas.

Conclusions. Considering a modern city, one can notice that it is in constant dynamics and development, experience a continuous equipment and supplementation with innovative technologies. 
The world is transforming, and every day new devices, technologies, measurements appear, somehow getting into the everyday life of the man. The city being an epicenter of the scientific thought is a "pioneer" in the "ocean" of innovations. It changes every minute - there are no longer any territorial restrictions for it, it is moving into new three-dimensional spaces, turning into a cybernetic city.

Using a variety of digital devices has both a positive and negative sides. A disordered implementation can gradually lead to a collapse of the urban environment, a loss of its historical authenticity and integrity. It is also important to meet the environmental and ergonomic requirements, comply with the principles of energy saving. All these issues remain relevant and important recently, as being in a continual chase after new digital technologies, the city loses its "face" and becomes a "decaying bunch" of diverse information. In other words, it becomes unnatural and empty.

It can be concluded that the city is a special object of research that requires a careful attention. The results of scientific studies of specialists from different areas should find their practical implementation, primarily in the development of the guidelines for creating a comfortable urban environment. The priorities and development trends should be identified at the level of a detailed consideration of the structural systems of the city including visual-communication environment.

It follows from the above that the visual-communication environment, which is a special hierarchical system of the city and acts as a carrier of innovations, is a relevant object for research and requires an in-depth study. Therefore, a primary objective for the modern city is a harmonious introduction of innovative technologies to create and maintain comfort and it can be achieved using a comprehensive master plan for the visual-communication environment.

\section{REFERENCES}

1. Glazychev V.L. (1984) Socio-ecological interpretation of the urban environment. Moscow: Science.

2. Faizullin F.S. (2008). Formation of a sociological school in Bashkortostan. Sociological Studies, (8), p. 88-94.

3. Trushchenko O. E. (1983) Urban environment and lifestyle. Criticism of American Sociological Concepts (Candidate's thesis). Moscow, Russia.

4. Ikonnikov A.V. (1973) Formation of the urban environment. Moscow: Knowledge.

5. Zhdanov N.V. (2016) Bionics for designers. Textbook for universities. Moscow: Yurayt.

6. Chaika V. (2018) Leonardo da Vinci. Inventions. Kiev: Lotos.

7. Negroponte, N. (2018). Architecture Machine: Nicholas Negroponte: Free Download, Borrow, and Streaming: Internet Archive. Retrieved from https://archive.org/details/NicolasNegroponteArchitectureMachine [Accessed 20 May 2018]

8. Soleri, P. (2006) Arcology - City in the image of Man. Paradise Valley, AZ: Cosanti Press.

9. Look at Me. (2019). Green architecture. [online] Available at: http://www.lookatme.ru/mag/archive/experienceother/120663-zelenaya-architektura [Accessed 10 Mar. 2019]

10. Hinte, E. (2003). Smart architecture. Rotterdam: 010 Publishers. 